\title{
A genealogia em uma analítica do poder: articulações e contrastes na representação LGBT publicitária
}

\author{
Anderson Scherer \\ Juliana Petermann \\ Universidade Federal de Santa Maria
}

\begin{abstract}
Resumo
O presente artigo parte de alguns estudos genealógicos de Michel Foucault com o objetivo de apontar possibilidades de aplicação metodológica para se realizar uma análise das relações de poder. De maneira mais específica encontrar indicações, regras de prudência, precauções de método e problematizações que possam ser utilizadas em uma analítica de poder que tem por objeto a representação LGBT na publicidade. Depreende-se uma análise capilarizada relações de poder entre publicidade e comunidade LGBT, a partir dos efeitos visíveis, das estratégias e táticas de resistência que escapam ao olhar de uma análise de poder vertical e por subordinação.
\end{abstract}

\section{Palavras-chave:}

Genealogia. Relações de Poder. Publicidade. LGBT.

\section{Introdução}

$\mathrm{O}$ artigo tem como tema de estudo os discursos e as práticas do mercado publicitário frente ao público LGBT. A publicidade regularmente correspondeu e legitimou a visão hegemônica de um dado tempo e espaço, da mesma maneira como colaborou para a composição dessa visão moral. Se avaliarmos o histórico da publicidade em relação a representação das minorias depreendemos um déficit significativo. Esse desnível é historicamente alvo e argumento das críticas de movimentos sociais (como o LGBT) direcionadas à publicidade. Os movimentos libertários que eclodiram nos anos $1970 \mathrm{e}$ que, entre outras pautas, debatiam a liberdade sexual e as identidades foram o estopim para mudanças significativas nas últimas décadas. Entre essas mudanças provenientes das reivindicações e pressões está a revisão dos discursos midiáticos, e por consequência publicitário, o qual levantamos nesse trabalho.

Estudos como o de André Iribure Rodrigues (2008) demonstram esse cenário. Rodrigues mapeou, quantificou e qualificou as representações LGBT em anúncios veiculadas da televisão brasileira desde a década de 1970 até 2008 . Seus estudos apontam para um aumento em nível quantitativo dessas representações durante as últimas dé-

Revista Ícone (ISSN 2175-215X) • DOI: 10.34176/icone.v17i2.239070

Recife, Vol. 17, N. 2, 125-141, ○ 2019 PPGCOM/UFPE.

Artigo recebido em 30 nov. 2018 e aprovado em 5 mai. 2019.

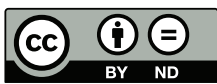


cadas. Por meio de um trabalho de interpretação desses anúncios por um olhar contemporâneo, tanto teórico quanto empírico, reconta a história da representação LGBT na publicidade relacionando-a com a trajetória do movimento, as pautas da mídia, o impacto do HIV e as discussões sobre sexualidade no espaço público, os estigmas atribuídos a esses grupos, assim como as mudanças sociais e de comportamento da sociedade brasileira nas últimas décadas.

Além disso, o estudo classifica qualitativamente toda a produção entre anúncios estereotipados, como aqueles que reforçavam o estigma e o discurso heteronormativo; e os desconstrucionistas como aqueles que quebravam de alguma forma a lógica cristalizada de preconceitos e estereótipos, mostrando representações mais responsáveis da comunidade LGBT. O estudo aponta a predominância de comerciais estereotipados, assim como, também pondera que, mesmo a passos lentos, a representação LGBT passa por um processo de revisão de seus discursos. O aumento dos anúncios desconstrucionistas e diminuição dos estereotipados é um indicativo dessa revisão de discurso.

Mas essa descontinuidade discursiva aqui alegada não se deu apenas por conta das pressões de movimentos sociais. Essa descontinuidade também acontece por meio e impulsionada pelo consumo. No mundo do marketing a expressão "gayfrien$d l y$ " é utilizada para caracterizar as marcas que mantém uma postura amigável com a comunidade LGBT. Em seus discursos enaltecem a diversidade, e repudiam práticas preconceituosas. Seus anúncios são principalmente veiculados nas redes sociais e majoritariamente lançados no período de junho, mês que comporta o dia dos namorados (no Brasil) e o dia do orgulho LGBT. A cada ano o número de marcas que incorporam a alcunha "gayfriendly" se intensifica e os debates e contestações em torno delas também. A crença no mundo no marketing é de que há na comunidade LGBT um foco de consumo com alto poder aquisitivo ${ }^{1}$. Dessa forma emerge um nicho de mercado a ser incluído pela comunicação.

Segundo Nunan (2003), levantamentos sobre os hábitos de consumo dos homossexuais como Gay and Lesbian Market Study (1997) realizado nos EUA, afirmam que a renda média mensal dos homossexuais (aqueles que assumem uma identidade homossexual) podem ser até 3 vezes maior que a média de renda mensal da população heterossexual americana. Há ainda outro nicho de estudos sobre os hábitos de turismo dos homossexuais. No mercado homossexual mundial, existem mais de 1200 empresas ligadas ao turismo homossexual e todas registradas na IGLTA (International Gay and Lesbian Travel Association).

Quando as marcas "gayfriendly" levantam a bandeira do arco-íris, parece haver um espectro de interpretações possíveis por parte dos públicos. Podem tanto serem

1 Estudos sobre os hábitos de consumo dos homossexuais como Gay and Lesbian Market Study (1997) realizado nos EUA, afirmam que a média mensal dos homossexuais (aqueles que assumem uma identidade homossexual) podem ser até 3 vezes maior que a média de renda mensal da população heterossexual americana. Há ainda outro nicho de estudos sobre os hábitos de turismo dos homossexuais. No mercado homossexual mundial, existem mais de 1200 empresas ligadas ao turismo homossexual e todas registradas na IGLTA (International Gay and LesbianTravelAssociation). Segundo dados desta organização, os homossexuais gastariam U\$2 bilhões em turismo anualmente. (NUNAN, 2003) 
enaltecidas por uma parcela dos consumidores, ou novamente alvos de críticas, por (supostamente) se utilizarem do movimento LGBT para dialogar com a comunidade, sem de fato incorporar esse apoio nas políticas e práticas da empresa, tornando esse um discurso vazio e apenas interessado no retorno financeiro.

Diante desse cenário, o objetivo do artigo é apontar possibilidades de aplicação metodológica a partir de uma perspectiva genealógica de análise histórica das relações desse contexto.

\section{O Pink Money}

O termo Pink Money (ou dinheiro-cor-de-rosa) se refere ao dinheiro advindo dos consumidores LGBT's. É utilizado, também, de maneira critica para se referir à segmentação do público LGBT, apenas pelo caráter mercadológico, sem procurar de alguma forma apoiar as pautas do movimento para além do lucro financeiro.

Recentemente a cantora pop Anitta, que é beneficiada pelo Pink Money por ter uma grande quantidade de fãs LGBT's, foi convocada a posicionar-se contra declarações homofóbicas do então candidato à presidência da República Jair Bolsonaro. $\mathrm{O}$ candidato foi condenado por dano moral coletivo, em novembro de 2017, pelo Tribunal de Justiça do Rio de Janeiro por declarações contra gays ${ }^{2}$. Outras duas cantoras Pablo Vittar e Ludimila -, também beneficiadas pelo Pink Money, romperam contratos publicitários com a grife Victor Vicenzza Calçados ${ }^{3}$ cujo dono declarou apoio ao candidato. Exigindo uma postura parecida, fãs, muitos deles pertencentes à comunidade LGBT, iniciaram uma campanha nas redes sociais levantando a hashtag \#AnittaIsOverParty e \#AnittaDigaNãoaoFascismo, além disso, ameaçaram boicotar a cantora, caso ela não se posicionasse contra o candidato ${ }^{4}$. Em um primeiro momento a cantora pareceu relutante em aderir à campanha, por fim, após diversos artistas se manifestarem repudiando o preconceito e a homofobia, a cantora Anitta acabou cedendo à pressão e gravou um vídeo onde se manifesta contrária às declarações do candidato. ${ }^{5}$

\section{Publicidade e relações de poder}

Rodrigues (2008) aponta para as contradições e a necessidade de se pôr em pauta as dualidades e conflitos entre os interesses de mercado, articulados diretamente à lógica capitalista em uma sociedade de consumo, com a pauta dos movimentos identitários de minorias.

2 Disponível em <https://www1.folha.uol.com.br/poder/2017/11/1934062-bolsonaro-e-condenado-a-pagar-r-150-mil-por-declaracoes-contra-gays.shtml>.

3 Disponível em <https://f5.folha.uol.com.br/celebridades/2018/09/ludmilla-rompe-contrato-com-marca-de-calcados-que-apoia-bolsonaro-assim-como-pablo-vittar.shtml> Acessado em 20 de Setembro de 2018.

4 Disponível em <https://catracalivre.com.br/cidadania/anitta-e-ameacada-de-boicote-por-causa-de-jair-bolsonaro/> Acessado em 20 de Setembro de 2018.

5 Disponível em <https://www1.folha.uol.com.br/ilustrada/2018/09/anitta-afirma-nao-apoiar-bolsonaro-em-resposta-a-daniela-mercury.shtml> 
Um modelo de cidadão-homossexual é normatizado, marginalizado, pela lógica do consumo, os que não se enquadram nesse segmento de mercado. Ao final, segue a contradição de incluir pela orientação sexual, e excluir pela classe social, o que reforçaria a lógica de uma hegemonia, que o movimento das minorias busca criticar e alterar. A sociedade de consumo reifica o modelo hegemônico, fazendo concessões como a de absorver uma parcela homossexual com poder de compra. A divisão desigual das relações de poder no que tange à orientação sexual não é colocada em discussão, e acaba sendo massacrada pela inclusão mercadológica. (RODRIGUES, 2008, p.50).

Amanda de Carvalho (2015), também se utiliza da mesma metodologia proposta por Rodrigues (2008), como forma de investigação da representação LGBT na publicidade de forma crítica e histórica. E também aponta para a necessidade de se considerar as relações de poder imbricadas para além dessas produções publicitárias.

As formas de representações permitem identificar as relações de poder intrínsecas nesse tema, as quais também refletem a postura das agências de publicidade, dos anunciantes, da própria sociedade brasileira, e, ainda, o que pode e o que não pode ser dito sobre as variantes de um modelo hegemônico. (CARVALHO, 2015, p.6).

Atualmente as formas de se fazer publicidade se diversificaram, se comparadas aos formatos clássicos, possibilitando a segmentação estratégica e o diálogo quase que cirúrgico com os públicos pretendidos por meio das redes sociais, por exemplo. Mas também, proporcionaram um meio de feedback ao público, que protesta, questiona, organiza-se e responde às marcas. Nesse sentido é que se observa que o debate sobre a real preocupação das marcas, ou com qualquer agente que lucre com a comunidade LGBT, vem ganhando notoriedade.

Os consumidores se mostram mais atentos aos discursos e suas atuações frente a causas socioambientais. Essa relação dialógica é defina por Wottrich (2017) como práticas de contestação:

Nesse cenário, emergem as práticas de contestação da publicidade, que confrontam a posição do receptor interator e produzem sentidos em dissonância com as estratégias publicitárias. Trata-se de um fenômeno novo, que o campo publicitário tem tentado, através de suas estratégias, assimilar. (WOTTRICH, 2017 p. 123).

Há, ainda, transformações no próprio mercado publicitário, as críticas e questionamentos em relação aos formatos e estruturas das agências entraram em pauta. Propostas alternativas e novos agentes começam a reformatar a cena do mercado publicitário. Entre aparentes reformas destacamos aqui as consultorias de nicho especia- 
lizadas em representatividade LGBT. A Pajubá - Diversidade em rede e Indánimo, são exemplos de modelos de negócio que aparecerem para pautar e colocar em discussão as relações de poder e as representações compromissadas e responsáveis com esses grupos minoritários. Na página oficial da marca na internet, Gustavo Bonfigliolli, um dos fundadores da consultoria, argumenta que a Pajubá é uma rede de consultores/as e ativistas LGBT (e de outros grupos minorizados) que prepara marcas e empresas para construir diversidades estruturais.

Nossa missão é orientar empresas que desejam contribuir para a inclusão, representação e capacitação de populações e culturas marginalizadas no mercado e nos demais espaços sociais, em todas as etapas do processo. Somos agentes de vivências: conectamos empresas com diferentes histórias para além dos prédios corporativos. Promovemos injeções de alteridade e senso de humanidade; um reality check. Para nós, a diversidade é a principal força motriz da criatividade". (BONFIGLIOLI, 2017).

Recentemente houve um caso que chama atenção e ilustra o cenário ao qual estamos tentando compreender. A Uber ${ }^{6}$, durante o mês de julho de 2018 realizou diversas ações e campanhas pró-comunidade LGBT. Para isso, convidou uma série de representantes e influencers para auxiliar na concepção de sua campanha. Nos canais digitais da marca, principalmente no YouTube, divulgou um vídeo case ${ }^{7}$ que mostra o processo de concepção do projeto com o auxílio dos influenciadores e representantes da comunidade. O projeto UberPride, contou com diversas ações, como levar 60 casais LGBTQI+ ${ }^{8}$ para se casar no mês de julho. Além disso, acompanhou paradas LGBT em diferentes estados do país, o que foi amplamente divulgado nas redes sociais oficiais da marca.

Em seu blog oficial a marca advoga ao seu favor e tenta legitimar seu discurso, listando as diversas ações realizadas com o objetivo de assegurar um compromisso com as pautas LGBT:

Faz ações de conscientização para motoristas parceiros. Ano passado, distribuiu 50 mil cartilhas propondo um código de conduta baseado no respeito. Este ano distribuirá 100 mil. Pelo aplicativo, continua veiculando para os 500 mil motoristas ativos e 20 milhões de usuários pílulas de informação que têm esse mesmo propósito: incentivar o respeito à diversidade. (Uber, 2018) $)^{9}$.

Entretanto, no mês seguinte a cantora travesti Linn da Quebrada fez uma denúncia em seu Twitter, afirmando ter sofrido preconceito de um dos motoristas da

6 Multinacional americana, prestadora de serviços eletrônicos na área de transporte privado urbano, através de um aplicativo de transporte.

7 Disponível em <https://www.youtube.com/watch?v=UKLwRQKAnkQ\&list=PLNd0i0_hUyNu1vsPmTIw7o-_G5i91Fa4K>. Acessado em 17 de Setembro de 2018.

8 Disponível em <https://www.youtube.com/watch?v=2WXYeXmAs20>.

9 Disponível em <https://www.uber.com/pt-BR/blog/sobre-uber-pride-no-brasil/> 
Figura 1 - Twitter oficial da cantora Linn da Quebrada. Página Oficial da Linn da Quebrada no Twitter.

Figura 2 - Posicionamento de usuário na rede social Twitter sobre a campanha UberPride. Página da Uber Brasil no Twitter.

Figura 3 - Respostas referentes a postagem da foto. Página da Uber Brasil no Twitter.

\section{Linn da Quebrada}

@linndaquebrada

Seguir

acabei de passar uma puta situação de constrangimentocom a @Uber_Brasile não é a primeira vez, lógico. Onde o motorista chega no local de embarque e se recusa a me deixar entrar no carro porque eu sou travesti. E aee @Uber_Brasil, já recalquei d problemas assim, de assédio..

19:33 - 20 de ago de 2018 de São Paulo, Brasil

387 Retweets 1.197 curtidas $(18) 20$ (2) \& 89

Q $55 \quad$ Ł๖ $387 \quad \bigcirc \quad 1,2 \mathrm{mil} \boxminus$

(2) Tweete sua resposta

Linn da Quebrada @ @inndaquebrada.2 h

E nada aconteceu.. eu que sou constrangida constantemente e seus motoristas continuam impunes e sendo beneficiados @Uber_Brasil

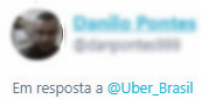

Seguir

MUITO bom Uber, qual a porcentagem dos lucros da empresa vai ser doada para ajudar os LGBT em situação de rua? Ou vocês acham que estão ajudando alguém com videozinho lacrador? Alguém pode desconfiar que vocês só querem Pink Money.

15:34 - 9 de ago de 2018

2 Retweets 18 curtidas $\rightarrow$ et P 9 9 980

Q 2 tI $2 \quad O_{18} \quad \square$

Em resposta a @Uber_Brasil 13 de ago
Entendi, vocês só tem eles como usuários? Porque não fizeram o mesmo com
outros eventos e outros segmentos?
outros eventos e outros segmentos?

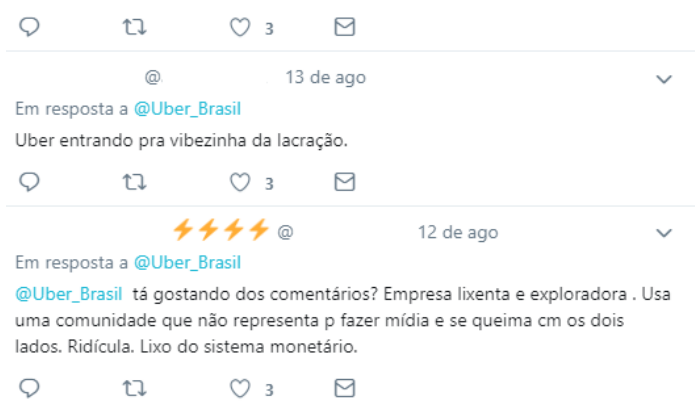


empresa.

A artista, também representante e formadora de opinião entre a comunidade, seguiu pedindo um posicionamento da empresa frente o ocorrido. A partir desse post da rede social, é possível perceber que a discussão se alonga entre pessoas que defendem a marca e outros que contestam a empresa.

Esses embates entre consumidores, marcas e ativistas se expandem, multiplicam, afloram, diminuem e desaparecem nas redes sociais oficiais das marcas gayfriendly, a todo o momento. Os defensores, os críticos, e até aqueles que rechaçam as marcas por defenderem LGBT's, com argumentos preconceituosos, entram em disputa. A discussão e os questionamentos da (possível ou não) legitimidade do mercado em abordar essas pautas parecem emergir. Por todos os lados surge o questionamento em relação ao mercado se apropriar das pautas LGBT's para vender, ou estar realmente engajado em uma nova representação das homossexualidades, usando da propaganda como aliada do movimento LGBT em prol de direitos e respeito.

É diante desse cenário de disputa discursiva que eu encontro meu tema de pesquisa. Mas, por onde começar? Como investigar esse cenário tão diverso? É em Michel Foucault que procuro um caminho para responder essas questões por meio de sua perspectiva genealógica para análise das relações de poder.

\section{O método genealógico de Michel Foucault}

Michel Foucault é um autor complexo, denso e com uma extensão de trabalho enorme, trabalhou com profundidade diversos temas ao longo de sua vida (a loucura, sexualidade, o crime). É um autor que não se define como próprio de um campo de estudos, não se limita a um tema de pesquisa. Pelo contrário, sempre esteve interessado em quebrar os lugares estabelecidos em romper com as fronteiras e definições. Durante seu percurso testa e aplica diversas estratégias metodológicas e problematizações. Muda facilmente de lugar, descola seus conceitos, e até se contradiz. É difícil encontrar em Foucault definiçõoes fechadas e finalizadas de conceitos. É um autor que praticamente não trabalha com conceitos, apesar de ter estabelecido alguns termos centrais para o entendimento de seu pensamento, como a sua abordagem genealógica. Por isso, tentar estabelecer um método fechado e dado a priori a partir de leituras de Foucault se torna um exercício extremamente anti-foucaultiano.

Há um importante aspecto no pensamento de Foucault no qual encontro uma alternativa e que se adequa as aspirações da presente pesquisa: sua ideia de "trabalho de campo em filosofia”. Isto é, com seu desdém por abordagens filosóficas abrangentes e abstratas, Foucault vai justamente pela via oposta e procura entender como empiricamente as práticas produzem efeitos por todo o campo social. Como lembra Rose "Foucault está mais interessado em investigar empiricamente as formas práticas e efetivas mediante as quais a filosofia produz o nosso mundo e a gama de práticas nas quais estamos engajados." (2016, p. 798). A ideia de um estudo e reflexão baseado no trabalho de campo e na empiria chama atenção e vem ao encontro com o tema o objeto de pesquisa. 
Tento em vista essas ressalvas, este artigo não se propunha a traçar um percurso genealógico único ou uma metodologia unitária e fixa. Mas por meio da leitura de textos de Michel Foucault, nos quais aborda o tema, o foco é procurar encontrar indicações, regras de prudência, problematizações.

Há ainda um outro ponto que justifica a escolha essa abordagem epistemológica. A recusa de Foucault em empreender teorias gerais em seus trabalhos analíticos. Em nenhum momento esteve disposto a conceber uma teoria geral do poder. $\mathrm{O}$ autor é bastante crítico a teóricos dispostos a conceber teorias com a ambição de serem aplicadas a qualquer situação como vantagem. Em contraste a ideia do teórico geral, pensa no teórico específico, trabalhando a partir da empiria com situações específicas e particulares e determinados a compreender as articulações locais entre poder, saber e subjetividade.

Para alcançar tal objetivo, partimos dos seguintes textos de Foucault: o capítulo metodológico de " $A$ vontade de saber", de 1976, onde formula a sua abordagem analítica do poder; a segunda aula do curso "Em defesa da sociedade", de 1976, na qual detalha suas precauções de método para análise das relações de poder; e um texto tardio, publicado originalmente por Dreyfus e Rabinow, nos Estados Unidos, no início dos anos 1980, intitulado, "O sujeito e o poder", no qual Foucault aborda a questão das práticas de resistência e das formas contemporâneas de luta e enfrentamento social.

\section{A genealogia como análise das relações de poder}

No capítulo metodológico de A História da Sexualidade - A Vontade de Saber (1976) Foucault está empenhado em estabelecer alguns parâmetros para a análise do poder. Longe de tentar cunhar uma teoria geral do poder, preocupa-se em estabelecer orientações gerais de como olhar para as relações de poder em suas análises genealógicas. Essas precauções são maleáveis e estratégicas, aptas para serem usadas de forma a guiar o pesquisador diante da construção de suas problematizações e objetivos. $\mathrm{O}$ objetivo dessa lista de parâmetros é curto-circuitar a linha geral de análise jurídica, isto é, a análise do poder por uma perspectiva da política moderna, que utiliza uma abordagem jurídico-discursiva.

Michel Foucault se afasta de uma analítica de poder pelo viés vertical, isto é, uma análise que perceba o poder apenas pelo seu caráter negativo em termo de opressão e dominação. Amplia seu olhar em todas as dimensões, e quebra com a unidade do dispositivo, o qual limita a um exame do poder centrado nas instituições e localizado no Estado como núcleo e fonte. Relações de poder não se manifestam apenas em termos de censura, interdição, repressão ou negação de existência.

Em contrapartida as "precauções de método" estabelecidas por Foucault emergem em um sentido de tentar olhar para as múltiplas sujeições que ocorrem e funcionam no interior do corpo social. Isto é, deve-se ter um olhar capilarizado das ações do poder. O poder não está fixo e dado nas instituições, nas leis, na macro estrutura capitalista de exploração geral, ou no Estado. O poder não tem lugar fixo, se estabelece nas relações, se alastra por toda a sociedade, e a todo o momento, como fluxos de 
movimentos que se deslocam produzem efeitos práticos, visíveis e analisáveis. Essa é a intenção de Foucault: não desconsiderar a existência do Estado das instituições ou do modelo capitalista, mas partir das macro estruturas para explorar os efeitos práticos, os pontos de resistência, as linhas de fuga desses movimentos de poder. Para isso, Foucault lembra-nos que devemos ter as seguintes precauções:

1. Não se trata de analisar as formas regulamentadas e legítimas de poder, e seus conjuntos de possíveis feitos ou aplicações. Isto é, a lei, os regulamentos, mas deve-se ir além dessas regras que orientam e delimitam o poder. "apreender o poder sob o aspecto da extremidade cada vez menos jurídica de seu exercício" (FOUCAULT, 1999 p.32).

2. Não se trata de se perguntar quem tem o poder afinal, pois o poder não tem substância, não é algo que se pode pegar, se deter, não está em nenhum lugar específico. Por isso, não devemos nos perguntar o que pensam (não é uma questão subjetiva), ou o que querem os executivos das marcas, os diretores de criação (pois o poder não está ali fixado), mas sim qual a intenção dessas relações, quais seus objetivos, seus alvos e seus campos de aplicação. Nas palavras do autor "como acontecem no momento mesmo, no nível, na altura do procedimento de sujeição ou mesmo nos processos contínuos e interruptos que sujeitam" (FOUCAULT, 1999 p. 33).

3. Não devemos olhar as relações de poder como uma força vertical aplicada, de cima para baixo, que produz um efeito de dominação massiva entre dominantes versus dominados. "Não se deve, acho eu, conceber o indivíduo como uma espécie de núcleo elementar, átomo primitivo, matéria múltipla e muda na qual viria aplicar-se, contra a qual viria bater o poder, que submeteria..." (FOUCAULT, 1999 p.35)

4. Deve-se fazer uma análise do poder capilarizada, isto é, a partir de suas extremidades, de seus efeitos práticos e analisáveis. Analisar a partir dos pontos de resistência. E sempre haverá resistência: lembra-nos o autor, "é preciso examinar o modo como, nos níveis mais baixos, os fenômenos, as técnicas, os procedimentos, se deslocam, se estendem, se modificam, mas, sobretudo, como eles são investidos" (FOUCAULT, 1999 p.36)

5. Não se trata de analisar o poder pelo viés ideológico, Foucault não trabalha com essa ideia de dominação ideológica, pois acredita que nos pontos mais baixos, na sua base, o poder não atua dessa forma. Trata-se de analisarmos os dispositivos de saber que disciplinam e normalizam comportamentos. "São instrumentos efetivos de formação e de acúmulo de saber, são métodos de objeção, técnicas de registro, procedimentos de investigação e de pesquisa, são aparelhos de verificação." (FOUCAULT, 1999 p. 40).

Michel Foucault, ainda sintetiza suas precauções de método da seguinte maneira: 
em vez de orientar a pesquisa sobre o poder para o âmbito do edifício jurídico da soberania, para o âmbito dos aparelhos de Estado, para o âmbito das ideologias que o acompanham, creio que se deve orientar a análise do poder para o âmbito da dominação (e não da soberania), para o âmbito dos operadores materiais, para o âmbito das formas de sujeição, para o âmbito das conexões e utilizações dos sistemas locais dessa sujeição e para o âmbito, enfim, dos dispositivos de saber. " (FOUCALT, 1999, p. 40)

Aplicando as precauções de método apontadas pelo autor à pergunta inicial que parecia ser o ponto principal de problematização da pesquisa, estaria o mercado se apropriando das pautas LGBT para vender? se torna limitada. Ao inserirmo-nos em uma perspectiva genealógica, amparados por Foucault, percebemos que não existe um único movimento coeso do mercado, ou da classe burguesa, opressora que se apropria de pautas de movimento de minorias como um grande plano de cooptação de consumidores. Tal pressuposição estaria localizando o poder em um lugar fixo, estaríamos colocando o poder como propriedade substancial de um grupo sobre outro. Estaríamos pressupondo que o poder, por meio da propaganda, agiria ora enganando, ora iludindo, mas o poder não procede por ideologia. Pelo menos não para Foucault.

A questão se torna mais complexa, e deveríamos, então, não perguntar se é uma questão de apropriação vertical, cruel e opressora; mas olhar os efeitos práticos, os efeitos de poder dentro das agências de publicidade, por exemplo. O olhar mais apropriado, a partir de Foucault, seria para dento das agências, das dinâmicas, das rotinas produtivas diante das pautas LGBTs. Deveríamos questionar como essas pautas são trabalhadas, como chegam, desde sua concepção até o produto final. As estratégias aplicadas, o "como se faz? ", os usos, as técnicas, as tomadas de decisões que escapam a lógica de subordinação "do mercado" no dia-a-dia. O interesse de Foucault sempre esteve na base, onde o poder se torna visível. Ou melhor, onde as relações de poder se manifestam: a microfísica do poder.

Mais do que isso devemos nos interessar pelos influenciadores, e formadores de opinião dentro da comunidade LGBT que participam, colaboram, e criam com as marcas. Artistas como Linn da Quebrada, que, ao mesmo tempo em que critica algumas ações do mercado, e questiona o real engajamento das marcas como no caso da Uber, mencionado anteriormente, também participa e colabora em outros projetos como na ação da marca Absolut. Intitulado "Quando a Arte Resiste o Mundo progride”, projeto que consiste em usar a arte para discutir temas de caráter político em estado de ebulição. Num dos países que mais mata transexuais no mundo ${ }^{10}$, a marca resolveu abordar a temática do preconceito estrutural ${ }^{11}$ contra as populações trans e travestis.

10 Mapa dos Assassinatos de Travestis e Transexuais no Brasil no ano de 2017 - ANTRA - Disponível em <https://antrabrasil.files.wordpress.com/2018/02/relatc3b3rio-mapa-dos-assassinatos-2017-antra.pdf $>$.

11 Excluídas do mercado de trabalho $90 \%$ da população Trans e Travesti acaba recorrendo a prostituição. Disponível em <http://especiais.correiobraziliense.com.br/transexuais-sao-excluidos-do-mercado-de-trabalho $>$. 

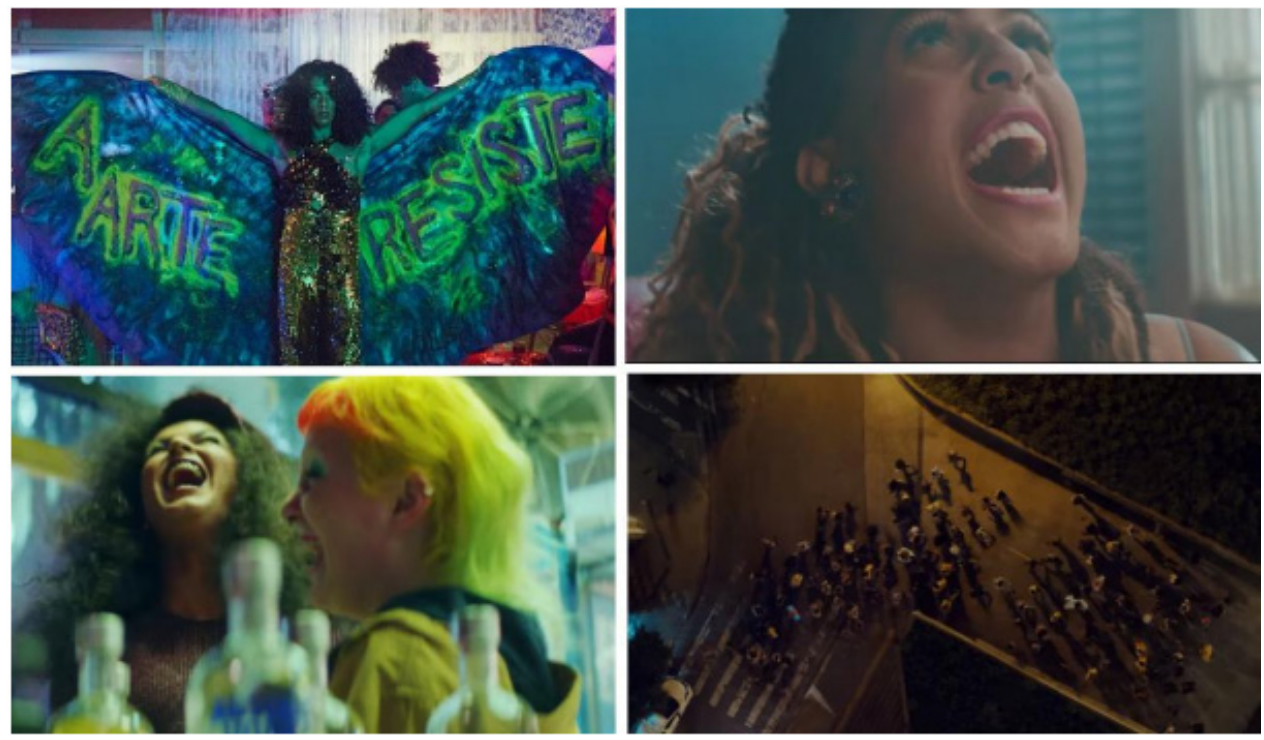

Figura 4 - Frames da campanha Absolutas. Reprodução/YouTube.

A campanha consiste em um vídeo, peça principal, e site especial para a campanha. Sob o mote "O Conservadorismo Pressiona", o objetivo da marca é discutir questões referentes à discriminação e exclusão dessa população através da promoção de artistas trans e travestis. Para tanto, as artistas Linn Da Quebrada, Raquel Virginia e Assucena Assucena foram convidadas para participar, e colaborar criativamente com a campanha. Ambas protagonizam o vídeo principal, sob o slogan "Quando a Arte Resiste, o Mundo Progride” a campanha se sustenta através de uma música, com composição de Linn Da Quebrada e participação das demais artistas. A marca financia, viabiliza e assina o vídeo que ilustra a composição das artistas trans. Em síntese, se trata de uma colaboração criativa da marca principalmente com a artista Linn Da Quebrada.

Não estaria, também, Linn da Quebrada se apropriando da visibilidade e audiência de uma marca internacionalmente conhecida, como meio para dar voz a sua música agressiva, política e forte em que usa do funk como pano de fundo para falar sobre homofobia, sexualidade e padrões de gênero? Se analisarmos os pontos de resistência e subversão, percebemos que nunca há uma apropriação total, uma subordinação por completo. É nesses lugares que a atenção deve ser redobrada em uma perspectiva genealógica.

Nesse sentido, parece mais frutífero perguntarmo-nos o quanto e até que ponto o discurso proveniente de setores sociais marginalizados (como a comunidade Trans), conseguem se apropriar da publicidade. Considerando as pautas indenitárias e as práticas de contestação dos consumidores devemos nos perguntar se e até onde conseguem fazer pressão, tencionar temas, e servir como um ponto de força que é capaz de produzir efeitos e subverter lógicas mercadológicas ocasionando a revisão de discursos. Dessa forma, o objeto da pesquisa se torna uma complexa rede de relações onde 
não há apenas dominantes e dominados, mas sim diversos agentes, interesses e um contexto a ser compreendido.

Para compreender o quão importante é, para a genealogia, realizar a pergunta adequada, ou melhor, o quanto que a pergunta irá determinar os rumos de tal genealogia, retomaremos algumas ideias básicas do olhar genealógico. A ideia de árvore genealógica familiar pode ajudar a orientar o olhar genealógico. Nesse tipo de exercício, a pessoa sobre qual será feita a árvore é o ponto de partida, e a partir dele a árvore irá ganhar ramificações, e estruturas a partir do protagonista da árvore. Caso o protagonista seja um primo ou mesmo um parente próximo a árvore ganharia estruturas e poderia chegar a lugares completamente diferentes. Ou seja, o ponto inicial de problematização é que irá conduzir o caminho da genealogia.

Portanto, em uma genealogia não há o interesse por uma perseguição intensa à origem, como em uma abordagem histórica, por exemplo. $\mathrm{O}$ problema ou ponto inicial é que irá conduzir e dar o tom da pesquisa e assim é ela que nos levará a "escavar a história a contrapelo". Não há uma origem única e especifica esperando ser encontrada que explique a emergência do tema de estudo aqui trabalhado. Devemos tomar as articulações e controvérsias do "pinkmoney" como um efeito, um efeito fruto de diversas circunstâncias, a intersecção de um conjunto heterogêneo contingencial e não necessário.

Fazer a genealogia dos valores, da moral, do ascetismo, do conhecimento não será, portanto, partir em busca de sua "origem", negligenciando como inacessíveis todos os episódios da história; será, ao contrário, se demorar nas meticulosidades e nos acasos dos começos; prestar uma atenção escrupulosa à sua derrisória maldade; esperar vê-los surgir, máscaras enfim retiradas, com o rosto do outro; não ter o pudor de ir procurá-las lá onde elas estão, escavando os bas-fond; deixar-lhes o tempo de elevar-se do labirinto onde nenhuma verdade as manteve jamais sob sua guarda. (FOUCAULT, 1984, p. 19-20).

\section{A genealogia como análise das resistências e diagnóstico do presente}

Michel Foucault, entretanto, não era um teórico do poder, seu principal tema e objeto de análise nunca fora o poder em si, por mais que esse tema tenha tocado por diversas vezes sua obra, o que Foucault se interessava era em entender como nos tornamos sujeitos. Em um primeiro momento estudou a objetivação dos sujeitos por meio dos discursos e dos jogos de verdade (arqueologia do saber); depois a objetivação dos sujeitos através das práticas de produção e individualização dos corpos (genealogia do poder); em um terceiro momento problematiza as formas de subjetivação, quando o sujeito se coloca como objeto de trabalho de si mesmo (genealogia da ética). Essas três ontologias do sujeito, propostas por Foucault, são como histórias do presente, ou seja, formas de análise crítica daquilo que somos, ou nos tornamos, de como fomos objeti- 
ficados enquanto sujeitos.

Para Foucault, o termo mais adequado para se pensar o poder, seria, portanto, conduta. Conduta como condução dos outros, condução pelos outros, e condução de si. Isso significa, também, que para nos orientarmos nessas perspectivas conceituais de poder como conduta dos sujeitos e análise das resistências, devemos olhar com prudência, pois, o que possibilita a condução de uns alguns sujeitos sob outros é uma série de diferenças sociais que dentro de um jogo de valores, hierarquizam e possibilitam ação de condução. Para a análise dessas diferenças e desníveis que irão possibilitar a condução e as resistências, Foucault chama atenção para uma série de instruções que podem ser tomadas como passos metodológicos. Devemos, então, analisar:

1. o sistema das diferenciações - diferenciações jurídicas, econômicas, sociais, étnicas, linguísticas, culturais, de habilidades e competência, que permitem agir sobre a ação de outros;

2. o tipo de objetivos perseguidos por aqueles que agem sobre a ação de outros;

3. as modalidades instrumentais, relativas às formas como o poder é exercido, seus modos de operação, suas regras, articulações, instrumentos e mecanismos aplicados, suas formas de controle;

4. formas de institucionalização - seus suportes institucionais, regulamentos, estrutura hierárquica - sua organização estratégica - e suas relações com dispositivos e aparelhos diversos;

5. os graus de racionalização, indicando o nível de elaboração e complexidade da tecnologia de poder empregada, expondo as racionalidades específicas que sustentam suas práticas.

Assim é partir das diferenças culturais e sociais dos profissionais do mercado; dos objetivos perseguidos pelos diferentes agentes no processo de comunicação e do movimento LGBT; dos instrumentos utilizados para se alcançar seus objetivos; das formas de institucionalização hierárquica dentro das agências e modelos de negócio; e das racionalizações usadas para explicar e argumentar algumas tomadas de decisões; que podemos de maneira genealógica desenhar como se dão as relações de poder.

Essas últimas perspectivas e pressupostos metodológicos se tornam cruciais para entendermos as estratégias dos diferentes fluxos e movimentos que aparecem no mercado.

As relações de poder se enraízam no conjunto da rede social. Isto não significa, contudo, que haja um princípio de poder, primeiro e fundamental, que domina até o menor elemento da sociedade; mas que há, a partir desta possibilidade de ação sobre a ação dos outros (que é co-extensiva a toda relação social) múltiplas formas de disparidade individual, de objetivos, de determinada aplicação do poder sobre nós mesmos e sobre os outros, de institucionalização mais ou menos setorial ou 
global, organização mais ou menos retida, que definem formas diferentes de poder. As formas e os lugares de "governo" dos homens uns pelos outros são múltiplos numa sociedade: superpõem-se, entrecruzam-se, limitam-se e anulam-se, em certos casos, e reforçam-se em outros. "(FOUCAULT, 1995, p. 247).

O genealogista deve encontrar os pontos de resistência e descrever as estratégias de luta dos agentes que se inserem nesse contexto. Podemos sintetizar: levando em conta a emergência da crítica às marcas que anunciam ao público LGBT, quais as estratégias empregadas pelos diferentes agentes que aparecem nesse processo? Se mudarmos o foco, percebemos que há muitas entrelinhas e variáveis que tornam a pesquisa mais rica e frutífera por meio do caminho genealógico de análise das relações de poder.

Resistência, entretanto, não está aqui empreendida em um sentido restrito como algo estritamente combativo, agressivo, daquele que se opõem de frente e diretamente a algo. Visão geralmente exercida pelos movimentos sociais. A perspectiva foucaultiana de poder explicitada anteriormente e a ideia de poder como condução, revela que resistência é mais abrangente que se opor unilateralmente. Estaria resistência, assim como a ideia de subversão e transgressão aqui defendidas, também relacionadas a formas de agência dos sujeitos. Agência aqui entendida como um uma força. Isto é, formas de produção de vida e subjetividade que como linhas de fuga contornam a atuação de um poder incisivo. Uma visão que aqui se defende percebe a resistência como uma força producente de inventar a nós mesmos e contestar cada vez mais as formas de ser projetadas sobre nós. Tem mais a ver com criar novas formas de conduzir nossas vidas e aos outros, sem necessariamente se opor diretamente a as estruturas ou bater de frente com as instituições.

As ideias aqui defendidas, podem ser ilustradas pelos casos relacionados a cantora Linn da Quebrada, que dentro de uma dinâmica de ordem capitalista inserida em uma sociedade de consumo, onde as mulheres e homens trans são empurrados para a marginalidade e excluída das dinâmicas sociais, vistas como seres abjetos, está mais interessada em sua própria agência e de forma criativa subverte os sentidos propostos por essa estrutura. $\mathrm{O}$ que de maneira nenhuma deixa seu trabalho menos crítico ou apolítico. Nikolas Rose resume:

O humano não é nem um ator essencialmente dotado de agência, nem um produto passivo ou uma marionete de forças culturais; a agência é produzida no curso das práticas, sob toda uma variedade de restrições e relações de força mais ou menos onerosas, mais ou menos explícitas, punitivas ou sedutoras, mais ou menos disciplinares ou passionais. Nossa própria "agência" é, pois, a resultante da antologia que nós dobramos sobre nós mesmos no curso de nossa história e de nossas práticas. (ROSE 2011, p. 262). 
Essa reflexão teve o intuito de estabelecer alguns parâmetros metodológicos, a partir das leituras de textos metodológicos de Michel Foucault, a fim de encontrar caminhos de problematização para se analisar as relações de poder imbricadas na representação LGBT na publicidade brasileira nos últimos anos. Também contou com as colaborações de Nikolas Rose, que toma a mesma base epistemiologica de Foucault pensada a partir de casos empíricos próprios do século XXI e por isso, em certo nível atualiza os pensamentos de Foucault.

Podemos afirmar que conseguimos ultrapassar os pressupostos e problematizações iniciais que vínhamos construindo para a pesquisa - se havia ou não apropriação das pautas LGBT's por parte do mercado apenas com fim comercial - e nos deparamos com um vasto campo de análise a partir dos efeitos práticos das relações de poder, e pontos de resistência. Problematização, essa, muito cara a análise genealógica. Percebemos que pode ser simplória demais uma visão de que há um movimento heterogêneo atuando de forma contínua e coesa, por toda a história, apropriando-se de pautas de grupos minoritários, como forma de apropriação para fins mercadológicos. Essa é a visão que a história convencional costuma contar. Mas o olhar genealógico demonstra que há pessoas, em diferentes contextos, diferentes cenários e nenhuma origem: há tensionamentos. Foucault nos orienta para olhar ações práticas, os efeitos visíveis, as estratégias e táticas de resistência que se capilarizam por todo o corpo social, que escapam o olhar de subordinação, autoritário e verticalizado das análises da "grande dominação capitalista”.

As leituras de Foucault realizadas por autores contemporâneos nos mostram as forças e potências de agências dos sujeitos em se (re) criar e se inventarem em meio as estruturas e as instituições.

\section{Referências}

ABSOLUT. ABSOLUTAS - Linn Da Quebrada feat. As Bahias e A Cozinha Mineira. <https:// www.youtube.com/watch?v=uunqc97qexU\&t=1s $>$ Acessado em 20 de setembro de 2018.

CATRACA LIVRE. Anitta é ameaçada de boicote por causa de Jair Bolsonaro. <https:// catracalivre.com.br/cidadania/anitta-e-ameacada-de-boicote-por-causa-de-jair-bolsonaro/> Acessado em 20 de setembro de 2018

CORREIO BRASILIENSE. Excluídas do mercado de trabalho $90 \%$ da população Trans e Travesti acaba recorrendo a prostituição. Disponível em $<$ http://especiais.correiobraziliense. com.br/transexuais-sao-excluidos-do-mercado-de-trabalho $>$ Acessado em 30 de novembro de 2018

F5 - FOLHA DE SÃO PAULO. Stylist de Ludmilla rompe parceria com marca de calçados que apoia Jair Bolsonaro. <https://55.folha.uol.com.br/celebridades/2018/09/ludmilla-rompecontrato-com-marca-de-calcados-que-apoia-bolsonaro-assim-como-pablo-vittar.shtml.> Acessado em 20 de setembro de 2018

FOUCAULT, M. Nietzsche, a genealogia e a história. in: MACHADO, R. (Org.). Microfísica do 
poder. Rio de Janeiro: Graal, 1984, p. 15-37.

Em defesa da Sociedade: Curso no Collège de France (1975 - 1976). São Paulo: Martins Fontes, 1999. P. 27 - 48.

. História da sexualidade I: a vontade de saber. Rio de Janeiro: Graal, 1988.

O sujeito e o poder. in: RABINOW, P. \& DREYFUS, h. M. Foucault: uma trajetória filosófica. Rio de Janeiro: Forense-Universitária, 1995, P. 231-249

. Vigiar e punir. Petrópolis: Vozes, 1987.

FILHO, P.K. A genealogia como método histórico de análise de práticas e relações de poder. Revista de Ciências Humanas, Florianopolis, v. 51, n. 2, p. 311-327, jul-dez 2017.

MEIO E MENSAGEM. Combate ao assédio. O que as agências estão fazendo? $<$ http://www. meioemensagem.com.br/home/comunicacao/2018/03/06/combate-ao-assedio-o-que-asagencias-estao-fazendo.html> Acessado em 20 de Setembro de 2018

Mapa dos Assassinatos de Travestis e Transexuais no Brasil no ano de 2017 - ANTRA Disponível em <https://antrabrasil.files.wordpress.com/2018/02/relatc3b3rio-mapa-dosassassinatos-2017-antra.pdf > Acessado em 30 de novembro de 23018

NUNAN, Adriana. Homossexualidade: do preconceito aos padrões de consumo. Rio de Janeiro: Caravansarai, 2003.

PAJUBÁ - Diversidade em rede. <https://gbonfiglioli.com/>. Acessado em 20 de Setembro de 2018

QUEBRADA, Linn da (@linndaquebrada). “acabei de passar uma puta situação de constrangimento com a @uber_Brasil e não é a primeira vez, lógico. Onde o motorista chega no local de embarque e se recusa a me deixar entrar no carro porque eu sou travesti. E aee @ uber_brasil, já recalquei d problemas assim, de assédio..." Twitter. 20 de agosto de 2018. 19:23. Disponível em < https://twitter.com/linndaquebrada> acessado em 30 de novembro de 2018 RODRIGUES, André Iribure. As representações das homossexualidades na publicidade e propaganda veiculadas na televisão brasileira: um olhar contemporâneo das últimas três décadas. 2008. 309p. Tese (Doutorado em Comunicação) -UFRGS, Porto Alegre, 2008. RODRIGUES, André Iribure; CARVALHO, Amanda de. Desde a Década de Setenta, em Setenta Comerciais: as representações LGBT na publicidade e propaganda veiculadas na televisão brasileira. In. X Alcar. Encontro Nacional de História da Mídia. 2015 ROSE, Nikolas. Inventando nossos Selfs. Psicologia, poder e subjetividade. Petrópolis - RJ. Vozes, 2011.

UBER. Sobre Uber pride no brasil. https://www.uber.com/pt-BR/blog/sobre-uber-pride-nobrasil/. Acessado em 26 de novembro de 2018.

UBER, Brasil (@uber_brasil) Disponível em <https://twitter.com/uber_brasil> WOTTRICH, Laura. "NÃO PODEMOS DEIXAR PASSAR”: práticas de contestação da publicidade no início do século XXI. 2017. Tese (Doutorado em Comunicação) UFRGS. Porto Alegre, 2017. 


\title{
Genealogy in an analytical power: articulations and contrasts in the representation of LGBT advertising
}

\begin{abstract}
The present article starts with some genealogical studies of Michel Foucault with the objective of pointing out possibilities of methodological application to carry out an analysis of the relations of power. In a more specific way find indications, rules of prudence, precautions of method and problematizations that can be used in a power analytic that has for object the LGBT representation in the advertising. Concludes a capillary analysis of power relations between advertising and LGBT community, from the visible effects, strategies and tactics of resistance that escape the look of a vertical power analysis and by subordination.
\end{abstract}

\section{Keywords}

Genealogy. Power relations. Advertising. LGBT.

\section{Sobre os autores}

Anderson Scherer. Mestrando do Programa de Pós-Graduação em Comunicação da Universidade Federal de Santa Maria (UFSM) na linha de pesquisa Mídia e Estratégias Comunicacionais sob orientação da Profa Dra. Juliana Petermann. Possui graduação em Comunicação Social Publicidade e Propaganda pela Universidade Federal de Santa Maria (2016). Integrante do grupo de pesquisa "Nós - Pesquisa Criativa" sob coordenação da Profa Dra. Juliana Petermann. andersonascherer@gmail.com

Juliana Petermann. Doutora em Ciências da Comunicação pela Universidade do Vale do Rio dos Sinos (UNISINOS). Possui graduação em Comunicação Social - Publicidade e Propaganda pela Universidade Federal de Santa Maria (2003), mestrado em Linguística Aplicada pela Universidade Federal de Santa Maria (2006). Atualmente é professora adjunta do Departamento de Ciências da Comunicação da Universidade Federal de Santa Maria e professora do Programa de Pós-graduação em Comunicação da mesma universidade. Atua principalmente nos seguintes temas: criação publicitária, ensino de criação publicitária, criatividade, marcas e seus discursos, estratégias de significação, análise de imagens publicitárias. Coordena o grupo Nós - Pesquisa Criativa (www.nospesquisacriativa.com). Recebeu o Troféu Reconhecimento da Associação Riogradense de Propaganda no ano de 2014. Foi escolhida professora do ano, recebendo o Prêmio Destaque em Ensino na Universidade Federal de Santa Maria no ano de 2017. É autora do livro Cartografia da Criação Publicitária.

petermann@ufsm.br 